\title{
ICRC Bacillus a Vaccine Candidate Strain (C-44) Is Coated with Human IgG
}

\author{
A. R. $\operatorname{Yadav}^{1 *}$, K. K. Mohanty², U. Sengupta ${ }^{3}$ \\ ${ }^{1}$ Department of Biochemistry, National JALMA Institute for Leprosy \& Other Mycobacterial Diseases (Indian Council of Medical \\ Research), Agra, India \\ ${ }^{2}$ Department of Immunology, National JALMA Institute for Leprosy \& Other Mycobacterial Diseases (Indian Council of Medical \\ Research), Agra, India \\ ${ }^{3}$ Shamshabad Road, Agra, India \\ Email: *sudama_ar@yahoo.com
}

How to cite this paper: Yadav, A.R., Mohanty, K.K. and Sengupta, U. (2017) ICRC Bacillus a Vaccine Candidate Strain (C-44) Is Coated with Human IgG. Open Journal of Immunology, 7, 45-50.

https://doi.org/10.4236/oji.2017.73004

Received: August 16, 2017

Accepted: September 5, 2017

Published: September 8, 2017

Copyright $\odot 2017$ by authors and Scientific Research Publishing Inc. This work is licensed under the Creative Commons Attribution International License (CC BY 4.0).

http://creativecommons.org/licenses/by/4.0/

\begin{abstract}
Indian Cancer Research Centre (ICRC) bacillus strain (C-44), a candidate vaccine against leprosy is cultured in vitro in Dubos medium enriched with amino acids and human serum. The study was conducted to find out whether ICRC bacilli obtained from these cultures are coated with anti mycobacterial antibody. Anti-ICRC antibody raised by intradermal inoculation of sonicated ICRC bacilli in rabbits reacted with both human immunoglobulin G (IgG) and antigens of ICRC. Further, ICRC bacilli could also be fluoresced directly with FITC labelled anti human IgG. Positive fluorescence of ICRC could be abolished by digestion of human IgG with trypsin and carbon tetrachloride $\left(\mathrm{CCL}_{4}\right)$. It is concluded that ICRC bacilli present in the vaccine are coated with human IgG.
\end{abstract}

\section{Keywords}

ICRC, Antibody, Immunofluorescence, IgG, Vaccine

\section{Introduction}

In 1958, Indian Cancer Research Centre (ICRC) bacilli were grown in vitro culture in a modified Dubos medium, supplemented with non-essential amino acids and 5\% human serum [1]. This strain of ICRC was noted to inhibit M. leprae growth in mouse foot pad [2]. Later, inoculation of ICRC bacilli $\left(10^{9}\right)$ was shown to convert lepromatous individuals from lepromin negativity to positivity along with induction of histopathological regression of lepromatous lesions. Considering the above observations, ICRC bacillus was considered for a trial as a candidate vaccine for leprosy [3] [4]. Intradermal inoculation of lepromatous pa- 
tients with the C-44 vaccine strain of ICRC resulted in lepromin conversion from negativity to positivity in $57.7 \%$ and $91 \%$ of lepromatous leprosy (LL) and borderline lepromatous (BL) patients respectively. The above mentioned encouraging results led research workers to conduct field trials to find out its protective efficacy against leprosy [5].

ICRC vaccine [ICRC bacilli suspended in phosphate buffered saline (PBS), $\mathrm{pH}$ $7.2]$ is administered by intra-dermal inoculation of $0.1 \mathrm{ml}\left(10^{9}\right.$ bacilli) in the deltoid region of the arm. This vaccine has been reported to evoke local reaction at the inoculated site in the form of pustules, ulcers [1] and enlargement of regional lymph nodes [1] [3] [6] between 3rd and 8th week of the post-vaccination period. Although pustules and sometimes ulcerations ultimately healed without consequences, the reason for the occurrence of such pustules and ulcerations and enlargement of draining lymph nodes induced by this vaccine has not been explained by the investigators. The present study was undertaken to find out whether ICRC strain which was used in the vaccine had any other biological component which might have been responsible for induction of pustules, ulcerations and lymph node enlargement in the vaccinated subjects.

\section{Materials and Methods}

\subsection{Preparation of ICRC Antigen}

ICRC vaccine (C-44) vials (human serum used for this batch was negative for both HIV and hepatitis B) were obtained from Dr. C.V. Bapat, Emeritus Medical Scientist, Indian Council of Medical Research, New Delhi, India. ICRC bacilli suspended in PBS were centrifuged at $8000 \mathrm{~g}$ to precipitate the organisms. After decanting the supernatant, the deposit of bacilli was washed thrice in PBS. ICRC organisms were then sonicated for 15 minutes at 100 watts on ice. The sonicated antigen was stored at $4^{\circ} \mathrm{C}$ and was used as soluble antigen of ICRC.

\subsection{Raising Antibodies against ICRC (C-44) in Rabbit}

Anti-ICRC antibodies were raised in a rabbit (out bred New Zealand strain rabbit) by hyper immunizing the animals with a total of 4 intra-dermal doses [each dose of $1.0 \mathrm{ml}$ emulsion of equal volumes of ICRC soluble protein $(100 \mu \mathrm{g})$ and Freund's incomplete adjuvant (Sigma, USA)] at weekly intervals. Hyper immunized serum was collected after 7 days of the $4^{\text {th }}$ injection.

\subsection{Ouchterlony's Gel Diffusion}

Hyper-immunized rabbit anti-ICRC antibody was tested against ICRC soluble antigens by agarose gel diffusion method [7]. Anti-ICRC rabbit antibody absorbed with anti human IgG was also tested against soluble antigens of ICRC and human IgG by the agarose gel diffusion method.

\subsection{Direct Immunofluorescence (IF) Staining}

Smears were made from ICRC bacillary suspension obtained from the vaccine 
vial on microscopic glass slides. After fixation of the smears in formalin vapour atmosphere the slides were washed thrice with PBS and were used for direct immunofluorescence (IF).

A set of slides with smears were rinsed in carbon tetra chloride $\left(\mathrm{CCL}_{4}\right)$ for 10 minutes at room temperature followed by digestion of the smears with $0.1 \%$ solution of trypsin in Tris- $\mathrm{HCl}$ buffer, $\mathrm{pH} 8.0$ for one hour [8]. After rinsing the slides (both untreated and CCL4 treated-trypsin digested smears) in PBS for 15 minutes, the wet preparation of the slides were subjected to direct IF by overlaying the smears with fluorescent isothiocyanate conjugated Goat anti-human IgG (FITC-GAHIgG) followed by incubation for $1 \mathrm{hr}$. at $37^{\circ} \mathrm{C}$ in a bread box with wet filter paper and kept at $37^{\circ} \mathrm{C}$ incubator (WISWO BOD, Thermotech L-700). The wet preparations of smears were examined under an inverted fluorescence microscope (Leitz GmbH \& Co. Germany).

\section{Results}

Both ICRC antigen and human IgG reacted with anti-ICRC rabbit serum in Ouchterlony's gel diffusion showing a line of identity (Figure 1(a)). An additional precipitin reaction line against ICRC antigen was also noted (Figure 1(a)). After absorption of anti ICRC rabbit serum with human IgG the antibody activity with human IgG was abolished keeping the reactivity with ICRC antigen only (Figure 1(b)).

ICRC bacilli from the vaccine vial subjected to direct IF staining using FITC-GAHIgG were found to fluoresce with yellowish green coloration under the fluorescent microscope (Figure 2(a)). On the other hand, when IgG was digested by treating the smears with $\mathrm{CCl}_{4}$ and trypsin solution ICRC bacilli did not show any fluorescence (Figure 2(b)).

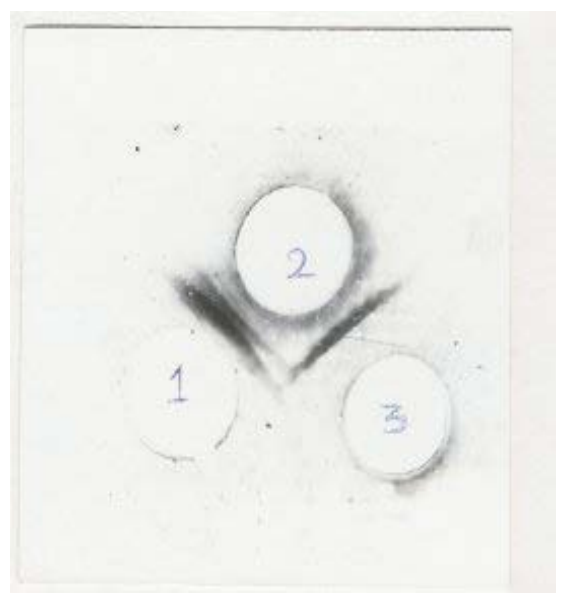

(a)

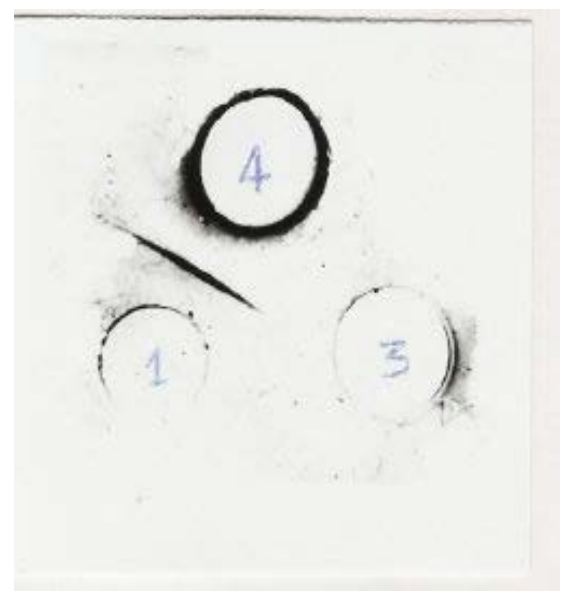

(b)

Figure 1. (a) Ouchterlony's gel diffusion in $1 \%$ agarose showing: (1) Sonicate of ICRC vaccine; (2) Rabbit anti-ICRC serum; (3) Human IgG (Sigma). (b) Ouchterlony's gel diffusion in 1\% agarose showing: (1) Sonicate of ICRC vaccine; (3) Human IgG (Sigma); (4) Rabbit anti-ICRC serum absorbed with human IgG. 


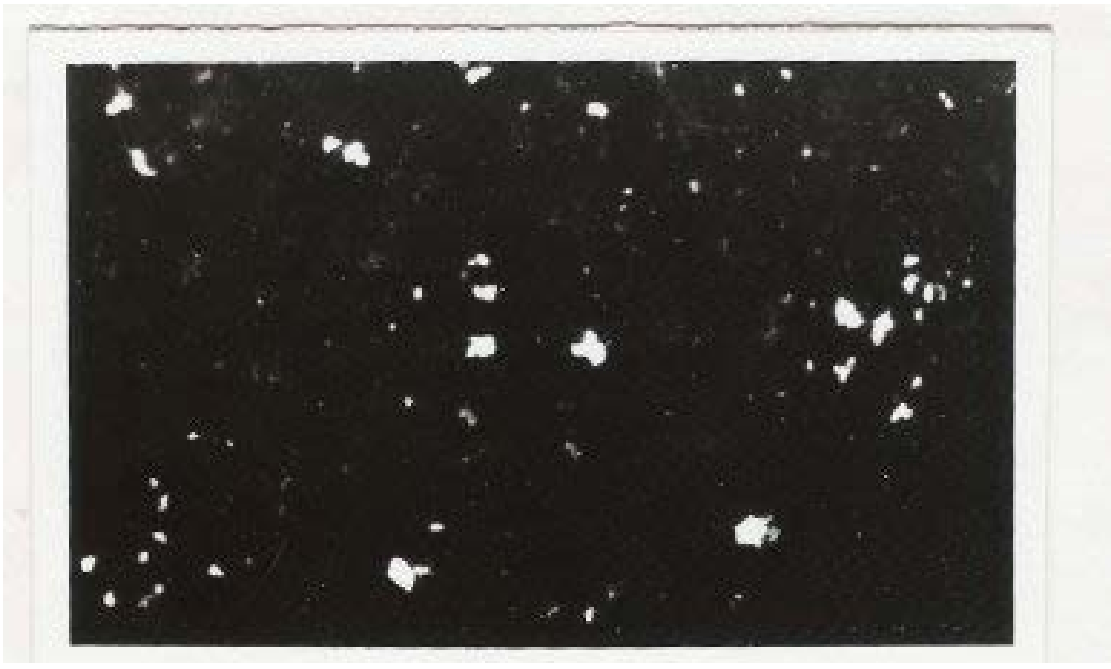

(a)

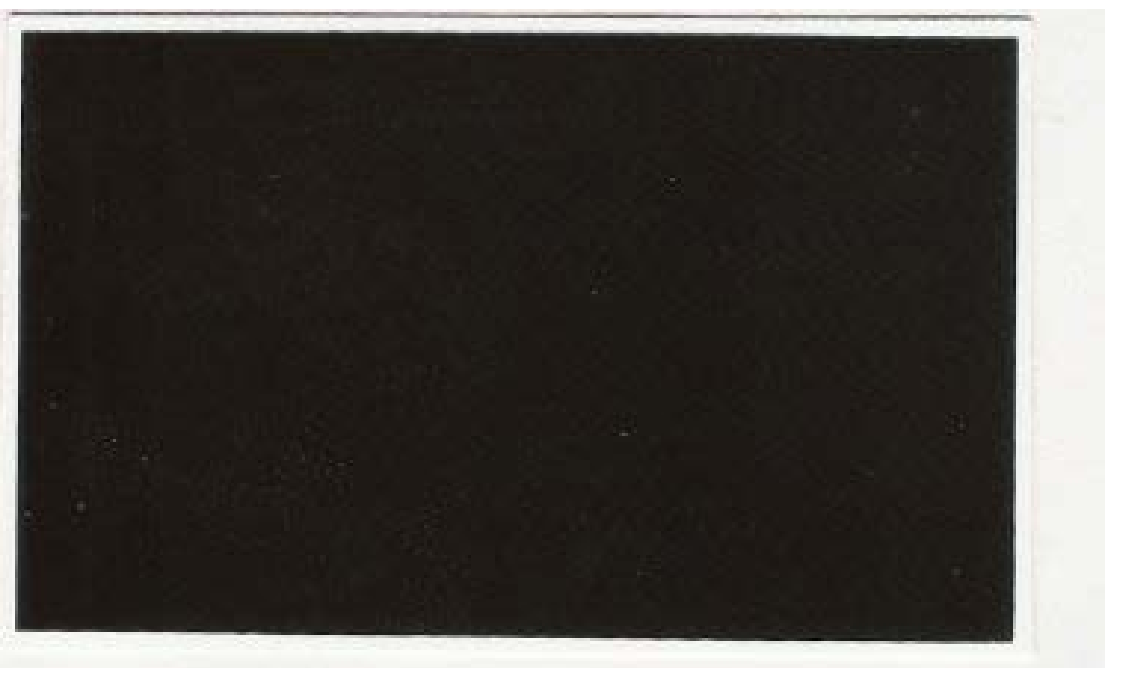

(b)

Figure 2. (a) ICRC bacilli showing fluorescence with FITC-goat anti-human IgG (Magnification X 400); (b) ICRC bacilli treated with carbon tetrachloride and $0.1 \%$ trypsin showing no fluorescence with FITC-goat anti-human IgG.

\section{Discussion}

It has been recently reported that ICRC vaccine provided maximum protection against leprosy out of all candidate vaccines which were evaluated for their efficacies in a South Indian endemic normal population, in a field area at Avadi. Further, out of all these vaccines, ICRC vaccine evoked hard skin indurations [1] [3], often leading to pustule formation [3] [6], ulceration [1] and lymphadenitis [1] [3]. These reactions indicated that ICRC bacilli must have recruited more immunoreactive cells liberating more interleukins which might have caused extensive granuloma formation. Out of four vaccines under trial BCG, $M . w$ is grown in bacteriological media and is purified as pure bacilli in the vaccine vial. M. leprae from armadillo tissue is purified by a WHO protocol and it does not contain any significant amount of foreign protein [9]. On the other hand, ICRC 
is grown in a human serum containing medium and is washed in PBS by centrifugation and is dispersed in aqueous suspension to contain $10^{9}$ bacilli/ml before irradiation. In the present study it was noted that ICRC bacilli could evoke antibody response not only to ICRC but also to human IgG when injected in rabbit as identified by precipitin reaction developed by gel diffusion (Figure 1(a)). However, earlier Rao et al. [10] were also able to detect only antibodies to human serum in rabbit sensitized with ICRC and not against any antigenic components of ICRC. Failure to detect antibody against antigens of ICRC [6] might be due to the use of suboptimal dose of ICRC antigen for immunization of rabbit. As the present study has hyper immunized rabbits using an optimal dose of ICRC protein, it could detect antibody against ICRC antigens and as well as human IgG.

Further, it was proved by direct immunofluorescence with FITC-GAHIgG that ICRC bacilli in the vaccine vial were coated with human IgG (Figure 2(a)). This was presumably due to coating of ICRC bacilli with cross reactive mycobacterial antibody present in the human serum which was in the culture medium. The treatment of bacilli with trypsin and $\mathrm{CCl}_{4}$ destroyed the IgG present on the bacilli as revealed by the negative reaction to direct binding of FITC-GAHIgG (Figure 2(b)).

The presence of ICRC bacilli along with its antibody (human IgG) is akin to the presence of molecules of antigen and antibody, i.e., immune complexes (ICs). These $10^{9}$ units of ICs might have evoked stronger and more prolonged immunogenic reactions in patients than those induced by other candidate vaccines which are simple suspensions of purified bacilli. Immune complexes are known to regulate the antigen uptake, processing and presentation to $\mathrm{T}$ cells [11]. Also internalization of immune complex was reported to have role in dendritic cell maturation and antigen presentation [12]. Thus, ICRC along with its antibody (human IgG) might have caused more local cellular infiltration with enlargement of draining lymph nodes.

The present study, therefore, indicates that the ICRC bacilli (C-44) in the vaccine are coated with human IgG. Therefore, ICRC vaccine might have evoked strong immune reaction in the individuals than other candidate vaccines due to the presentation of the antigens in the form of ICs. However, as human serum is incorporated in the culture medium, a close watch should be kept to screen human serum for the presence of any infectious agents specially hepatitis and AIDS viruses.

\section{Acknowledgements}

The authors thanks to Dr. C. V. Bapat, Emeritus Medical Scientist, Indian Council of Medical Research, New Delhi, India for providing ICRC vaccine vials for experiments.

\section{Conflict of Interests}

The authors declare that they have no conflict of interests. 


\section{Authors' Contribution}

U Sengupta conceptualized the study. U Sengupta and KK Mohanty designed the study protocol. AR Yadav performed the experiments. All authors have contributed for writing the manuscript and editing it.

\section{References}

[1] Deo, M.G., Bapat, C.V. and Chullawalla, R.G. (1981) Potential Anti-Leprosy Vaccine from Killed ICRC Bacilli-A Clinicopathological Study. Indian Journal of Medical Research, 74, 164-177.

[2] Bhide, M.B., Pradhan, K.S., Bapat, C.V., et al. (1978) A Vaccine from ICRC Bacilli against $M$. leprae Infection in Mouse Foot-Pad. Indian Journal of Leprosy, 50, 334-344.

[3] Deo, M.G., Bapat, C.V., Bhalerao, V., et al. (1983) Antileprosy Potentials of ICRC Vaccines: A Study in Patients and Volunteers. International Journal of Leprosy and Other Mycobacterial Diseases, 51, 540-549.

[4] Bhatki, W.S., Chulawala, R.G., Bapat, C.V., et al. (1983) Reversal Reaction in Lepromatous Patients Induced by a Vaccine Containing Killed ICRC Bacilli-A Report of Five Cases. International Journal of Leprosy and Other Mycobacterial Diseases, 51, 466-472.

[5] Gupte, M.D., Vallishayee, R.S., Anantharaman, D.S., et al. (1998) Comparative Leprosy Vaccine Trial in South India. Indian Journal of Leprosy, 70, 369-388.

[6] Vallishayee, R.S., Gupte, M.D., Anantharaman, D.S., et al. (1996) Post-Vaccination Sensitization with ICRC Vaccine. Indian Journal of Leprosy, 68, 167-174.

[7] Ouchterlony, O. (1962) Diffusion-In-Gel Methods for Immunological Analysis II. In: Kallos, P. and Waksman, B.H., Eds., Progress in Allergy Vol.VI, Karger, Basel/New York, 30-154. https://doi.org/10.1159/000391328

[8] Abe, M., Izumi, S., Saito,T., et al. (1976) Early Serodiagnosis of Leprosy by Indirect Immonofluorescence. Indian Journal of Leprosy, 48, 272-276.

[9] World Health Organization (1976) Report of the Second IMMLEP Task Force Meeting, 1-5 December, 1975. Leprosy Review, 47, 313-332.

[10] Rao, S.S., Nadkarni, J.S. and Khanolkar, V.R. (1964) Immunologic Studies with Mycobacterium leprae and Acid-Fast Mycobacterium Cultivated from Human Leprosy Nodules. Indian Journal of Leprosy, 32, 103-116.

[11] Manca, F., Fenoglio, D., Li, P.G., et al. (1991) Effect of Antigen/Antibody Ratio on Macrophage Uptake, Processing and Presentation to T Cells of Antigen Complexed with Polyclonal Antibodies. Journal of Experimental Medicine, 173, 37-48. https://doi.org/10.1084/jem.173.1.37

[12] Regnault, A., Lankar, D., Lacabanne, V., et al. (1999) Fc $\gamma$ Receptor-Mediated Induction of Dendritic Cell Maturation and Major Histocompatibility Comlex Class 1-Restricted Antigen Presentation after Immune Complex Internalization. Journal of Experimental Medicine, 189, 371-380. https://doi.org/10.1084/jem.189.2.371 
Submit or recommend next manuscript to SCIRP and we will provide best service for you:

Accepting pre-submission inquiries through Email, Facebook, LinkedIn, Twitter, etc. A wide selection of journals (inclusive of 9 subjects, more than 200 journals)

Providing 24-hour high-quality service

User-friendly online submission system

Fair and swift peer-review system

Efficient typesetting and proofreading procedure

Display of the result of downloads and visits, as well as the number of cited articles Maximum dissemination of your research work

Submit your manuscript at: http://papersubmission.scirp.org/

Or contact oji@scirp.org 